\title{
Nurses' Performance Regarding Administration of Inotropic Medications for Critically Ill Patients
}

\author{
Dr. Amal Bakr Abo El - Ata, Dr. Mona Hassan Ibrahim, Dr. Amira Saad \\ Mohamed, Mohamed Elsayed Ahmed Allawy \\ Assist Professor of Medical Surgical Nursing Faculty of Nursing Port Said University, \\ Lecturer of Medical Surgical Nursing Faculty of Nursing Suez Canal University, \\ Lecturer of Clinical Pharmacology Faculty of Medicine Suez Canal University, (B. Sc. \\ Nursing, Faculty of Nursing) (Port-Said University)
}

\begin{abstract}
Background, inappropriate administration of inotropic medications can lead to devastating and harmful effects to critically ill patients and nurses have a great responsibility for administration of these medications, this study aimed to assess nurses' performance regarding administration of inotropic medications for critically ill patients. Design: A descriptive research design was used in the study. Setting: the present study was carried out at Critical Care Units affiliated to the Suez Canal University Hospital and General Hospital in Ismailia city. Sample: A convenient sample of all staff nurses (90 nurses) included the pilot study who were working at the previously mentioned settings. Tools of data collection: The data were collected using three tools (nurses' Knowledge Assessment Questionnaire, Nurses' observational checklist and Nurses' Attitude Questionnaire. Results: The majority of nurses had an unsatisfactory level of knowledge and the majority of studied nurses had unsatisfactory total practice with nearly most of studied nurses had a positive attitude toward administering inotropic medications. Conclusion: there was a highly positive correlation between nurses' practice and nurses' knowledge and there was a positive correlation between the nurses' attitude and their knowledge and practice. Recommendations: Provide educational and training program and upgrading courses supported with evidence based practices and guidelines for appropriate administration of inotropic medications.
\end{abstract}

Keywords: Nurses' Performance, inotropic medications, critically ill patients. 


\section{INTRODUCTION}

Administering medications is one of the most crucial nursing responsibilities. Nurses are responsible for the preparation and administration of high alert drugs that affect the patient's cardiovascular and hemodynamic functions. To ensure safe and effective drug therapy for the patients, nurses need to be familiar with the indications, customary dosages, and intended effects of prescribed drugs, and nurses need to assess each patient before administering a drug, delaying or withholding it if necessary. Just as important, nurses need the skills to be able to administer a drug capably, minimizing your patient's anxiety and maximizing the drug's effectiveness (Perry et al., 2014).

Moreover, in the critically ill patient care, the use of inotropes could be a possibly lifesaving treatment. An understanding of the pathophysiology of the numerous types of shock and pharmacology of the medications used in the treatment of shock is important for intensive care unit nurses to take suitable decisions regarding inotropes indications and evaluate their effectiveness (Allen, 2014).

Also, inotropic medications increase myocardial contractile activity independent of changes in heart rate. Inotropic medications increase heart rate and some types of these medications have direct or indirect vasodilation properties for improving systolic performance. Inotropes are always used in intensive care units to stabilize heart failure patients (Sonawane et al., 2016). Inotropic medications have numerous pharmacological effects and drug selection according to the clinical profile leads to maximizing benefits while minimizing adverse effects. Epinephrine is the drug of choice in emergencies (cardiac arrest, anaphylaxis). Additionally, Inotropes are commonly administered by infusion pump in the critical care units to allow close monitoring and careful titration. The combined use of numerous inotropes in low doses may confer a benefit over single inotropic medication used at high dose (Palmer and Trinh, 2012).

On one hand, critical care nurses need to have deep understanding of inotropes is important for safe and effective care delivery. These highly potent medications can result in adverse events for patients if there is lack of nurse's performance regarding their use. The use of inotropes is an integral treatment in critical care units; so, the nurse has the responsibility to acquire a high level of knowledge on indications for 
inotropes, and their effects if high quality patient care is needed to be achieved (Parry, 2012).

On the other hand, nurses are faced with the ever-challenging responsibility of ensuring safe and effective drug therapy for their patients. Nurses must integrate this information into their patient care quickly and in an informed manner. Nurses should be competent enough in medication administration to prevent medication errors. Each nurse should be aware of indication, action, contraindications, adverse reactions and interactions of drugs (Kizior and Hodgson, 2016).

\section{AIM OF THE STUDY:}

This study aimed to assess nurses' performance regarding administration of inotropic medications for critically ill patients.

\section{Research questions:}

- What is the nurses' knowledge regarding the administration of inotropic medications for critically ill patients?

- What is the nurses' practice regarding the administration of inotropic medications for critically ill patients?

- What is the nurses' attitude regarding the administration of inotropic medications for critically ill patients?

- What is the relation between nurses' knowledge, practice and attitude?

\section{SUBJECTS AND METHOD:}

\section{Research design:}

A descriptive design was utilized in this study

\section{Research setting:}

The present study was carried out at Critical Care Units affiliated to the Suez Canal University Hospital (Cardiac Care Unit, Intensive Care Unit and Cardiothoracic Surgery Unit) and General hospital in the Ismailia city (Intensive Care Unit and Cardiac Care Unit. 


\section{Sample and Sample technique:}

A convenient sample of all nurses (males \& females) working at the previously mentioned setting regardless their age, years of experience, level of education. The size of the sample was ninety. (Total number $=90$ ) included the pilot study (70 nurses worked in Suez Canal University Hospital and 20 nurses worked in General hospital in the Ismailia city.

\section{Tools:-}

\section{TOOL (I): nurses' Knowledge Assessment Questionnaire}

The knowledge questionnaire sheet was developed by the researcher after reviewing of recent related literature to assess nurses' knowledge about inotropic medications in critical care units. It's composed of two parts:

Part I: It is concerned with demographic data of the studied nurses (e.g. Age and qualification, and work related data (department, years of experience and attending training courses related inotropic medications) and it includes 5 questions.

Part II: It includes six items regarding knowledge-related general pharmacological concepts of inotropic medications, knowledge-related adrenaline, knowledge-related to noradrenaline, knowledge-related to dopamine, knowledge-related dobutamine and knowledge-related to digoxin

The total score of nurse's knowledge against 34 questions was calculated to be 34 . The respondent was given one point for each correct answer and zero for incorrect answers. A total score below $70 \%$ was considered unsatisfactory, while those equal to or above $70 \%$ were considered satisfactory.

\section{TOOL (II): nurses' practice observational checklist:}

An observational checklist was developed based on the literature (Kizior and Hodgson, 2016 and Samy, 2014) to assess nurses' practice regarding the administration of inotropic medications via Infusion pump (Adrenaline, Noradrenaline, Dopamine, Dobutamine) and Digoxin by intravenous route. It was written in the English language to be collected by the investigator. It's composed of three parts covering the following areas: 


\section{Part (1): preparing phase divided into 2 parts}

- Preparing phase for inotropic medications given through an infusion pump (Adrenaline, Noradrenaline, Dopamine, Dobutamine) and it included 6 items of practical skills and how they were done to one degree for each item

- Preparing phase for inotropic medications given through the intravenous route (digoxin drug) and it included 5 items of practical skills and how they were done to one degree for each item.

\section{Part (2): Administrating phase divided into 2 parts}

- Administrating phase for inotropic medications given through an infusion pump (Adrenaline, Noradrenaline, Dopamine, Dobutamine) and it included 32 items of practical skills and how they were done with one degree for each item divided into the following sections:

- Nine items for general steps in administrating phase.

- Seven items for administrating adrenaline.

- Five items for administrating noradrenaline.

- Seven items for administrating dopamine.

- Foure items for administrating dobutamine.

- Administrating phase for inotropic medications given through the intravenous route (digoxin drug) and it included 4 items of practical skills and how they were done with one degree for each item.

\section{Part (3): Post procedure phase divided into 2 parts}

- Post procedure phase for inotropic medications given through an infusion pump (Adrenaline, Noradrenaline, Dopamine, Dobutamine) and it included 7 items of practical skills and how they were done to one degree for each item divided into the following sections:

- Foure items for general steps in post procedure phase.

- Three items for documentation phase.

- Post procedure phase for inotropic medications given through the intravenous route (digoxin drug) and it included 7 items of practical skills and how they were done to one degree for each item divided into the following sections: 
- Foure items for general steps in post procedure phase.

- Three items for documentation phase

The total score of the nursing practices was calculated to be 62 of the 62 items of steps. The possible choice for each item was done and not done. Each nurse was given one scores for step done and zero for that was not done. A total score of $70 \%$ and more was considered satisfactory, while a score below $70 \%$ was considered unsatisfactory.

\section{TOOL (III): Nurses' Attitude Scale}

Likert Type Rating Scale: It was adapted (Thomas and Johnson, 2013), modified by the researcher to assess nurses 'attitude regarding the administration of inotropic medication, it was rated on two dimension scale (yes or no) and it was modified into three likert scale (agree, indifferent and not agree). It has positive dimensions including 11 items with three responses (agree, indifferent, disagree) and negative dimensions including 6 items with three responses (agree, indifferent, disagree).

As regards Likert Type Rating Scale, scores of 1, 2 and 3 were respectively given to the responses of disagree, indifferent and agree. The scoring was reversed for negative items. The total score of the scale was 51 grades, the attitude was considered to be positive if the score was more than or equal to 35 grades, while it was considered to be indifferent if the score was ranging from 18 to less than 35 grades and it was considered to be negative if the score was less than 18 grades.

\section{Operational Design:}

It was entailed under the following 4points:

1- Preparatory phase

2-Content validity

3-Piloting of the study tool

4 -Field work description

\section{1-Preparatory Phase:}

A review of the past and current related literature covering various aspects of the problem, using available books, articles, periodicals and magazines to get acquainted with the research problem and develop the study tools (Parry, 2015). 


\section{2-Content Validity of the Tool:}

The tool was tested for its content validity, comprehensiveness and applicability by 9 expertise of professors and lecturers from the medical, surgical department in Faculty of Nursing, Port Said University and Faculty of nursing, Suez canal university and faculty of medicine, Suez canal university who revised the tools and modifications were done according to their opinion with a content validity index (. 8).

\section{3-Reliability:}

It was done using Cronbach alpha coefficient to assess the internal consistency of the tool and its value was $(0.82)$ for knowledge tool and (0.75) for attitude.

\section{4- Pilot study}

Tool of data collection was tested on ten percent of subjects and they were excluded from the entire sample of research study. The purpose of the pilot study is to test the applicability of study tools and to estimate the time needed to fill it. The results of the data obtained from the pilot study helped the researcher to modify the tools: items were corrected or added as needed. Accordingly, modifications were done and the final form was developed (Example, arabic translation of the word confusion).

\section{Field work:}

Once permission was granted to proceed with the proposal; Nurses agreed to take part in the study and they were individually interviewed and contacted by the researcher to clarify the purpose of the study. The knowledge questionnaire sheet was done by the nurses while on-duty and it was distributed to be answered within (30-40 minutes) then, their practices were observed by the researcher through observational checklist. The data collection started from the beginning of February 2017 to the end of July 2017. Over a period of 6 months 3days/week starting according to nurses' schedule for attendance to the hospital and availability of time for both nurses and the unit.

Data collected through the questionnaire and observation checklist were coded, entered using MS excel software. Data was then imported into Statistical Package for the Social Sciences (SPSS version 20.0) for analysis. Chi Square test was used for categorical data. Correlations were used to test relationships between different variables. $\mathrm{P}$ value was set at $<0.05$ for significant results 


\section{RESULTS:}

Table (1): shows that, $81.5 \%$ of studied nurses' age was between 20 to less than 30 years with mean age $26.04 \pm 3.53$. Also, $61.7 \%$ of studied nurses had technical degree

Figure (1): illustrates that, about $67 \%$ of studied nurses years of experience were between 1-6 years, $21 \%$ were greater than 9 years, while $12 \%$ were between 6-9years

Figure (2): (reveals that, $75 \%$ of studied nurses did not attend courses regarding inotropic medications while, only $25 \%$ who attended courses.

Figure (3): reveals that, $79 \%$ of studied nurses had unsatisfactory total score of knowledge regarding inotropic medication while only $21 \%$ of studied nurses had a satisfactory total score of knowledge

Figure (4): $\% 89$ ،(of nurses had a satisfactory total practice score, while only $11 \%$ of nurses had an unsatisfactory total score.

Figure (5): shows that $96 \%$ of studied nurses had positive attitude toward administering inotropic medications while only, $1 \%$ had negative attitude toward administering inotropic medications and 3\% had indifferent attitude toward administering inotropic medications.

Table (2): reveals that, there was a positive significant correlation between total knowledge scores and demographic characteristics (for education are $=\mathbf{0 . 2 7}$ and $\mathbf{p}$ value $=\mathbf{0 . 0 1 2}$ ) and work related data (for courses $(\mathbf{r}=\mathbf{0 . 2 7}$ and $\mathbf{p}$ value $=\mathbf{0 3}$ )

Table (3): illustrates that, there was a positive significant correlation between total practice scores and work related data (education $\mathbf{r}=\mathbf{0 . 2 8}$ and $\mathbf{p}$ value $=\mathbf{0 . 0 1}$ )

Table (4): depicts that, there was a highly statistically significant difference between total knowledge score and total practice score $(\mathbf{p}$ value $=\mathbf{0 . 0 0 2} * *)$

Table (5): reveals that, there was a positive significant correlation between attitude scores and total knowledge $\left(\mathbf{r}=\mathbf{0 . 2 5}{ }^{*}\right.$ and $\mathbf{p}$ value $\left.=\mathbf{0 . 0 3} *\right)$ and total practice scores $(\mathbf{r}=$ $0.26^{*}$ and $p$ value $=.02^{*}$ ). 
Table (1): shows that, $81.5 \%$ of studied nurses' age was between 20 to less than 30 years with mean age $26.04 \pm 3.53$. Also, $61.7 \%$ of studied nurses had technical degree

\begin{tabular}{|c|c|c|}
\hline \multicolumn{2}{|c|}{$\begin{array}{c}\text { Total Sample } \\
(n=81)\end{array}$} & \multirow[t]{2}{*}{ Variables } \\
\hline Percentage & Number & \\
\hline \multicolumn{3}{|r|}{ Age (Years) } \\
\hline 81.5 & 66 & $20:<30$ years \\
\hline 18.5 & 15 & 30: < 40 years \\
\hline \multicolumn{2}{|c|}{$26.04 \pm 3.53$} & Mean+SD \\
\hline \multicolumn{2}{|c|}{$21-35$} & Range \\
\hline \multicolumn{3}{|r|}{ Education } \\
\hline 9.9 & 8 & Bachelor degree \\
\hline 61.7 & 50 & Technical Institute \\
\hline 28.4 & 23 & Diploma \\
\hline
\end{tabular}

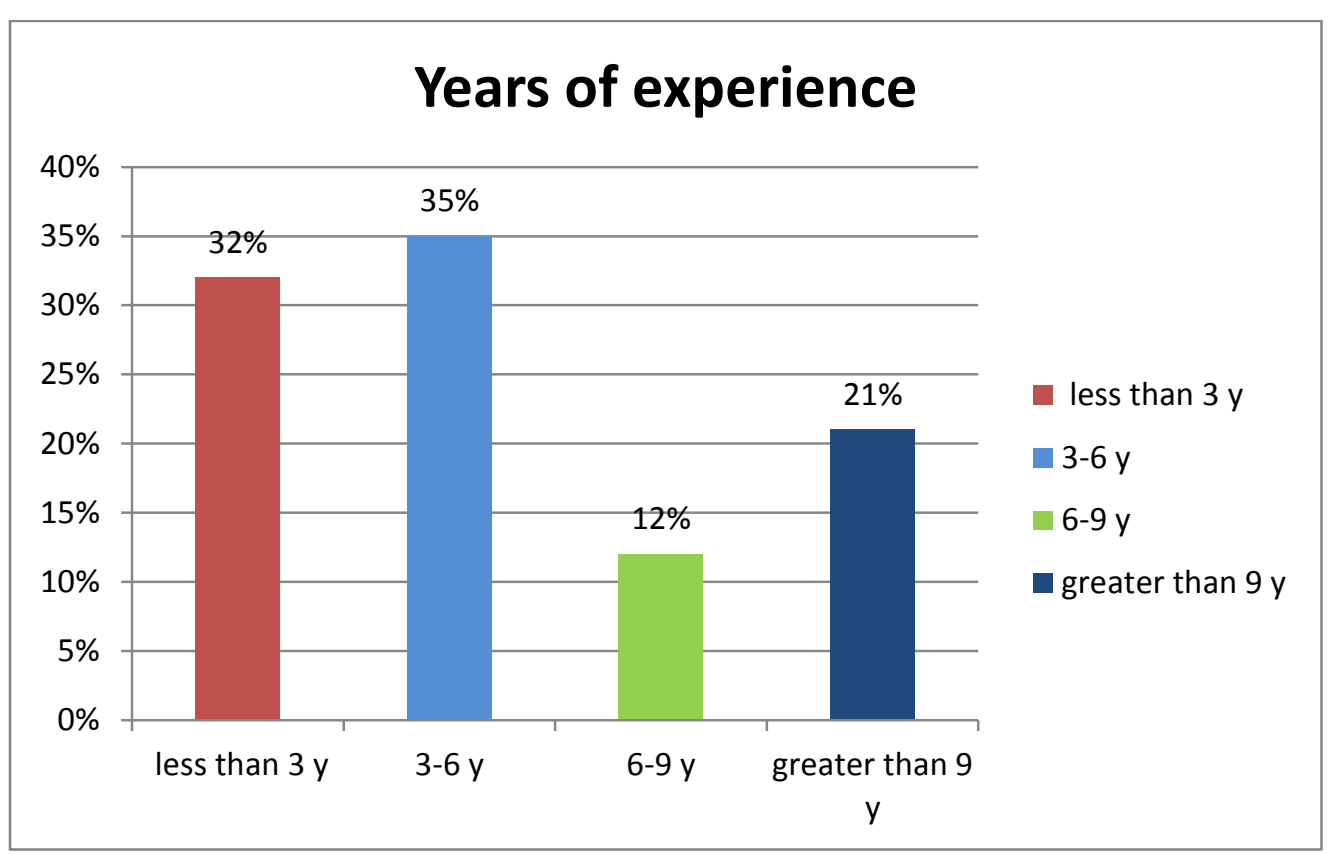

Figure (1): Distribution of the studied nurses according to their years of experience $(\mathrm{n}=81)$ 


\section{Percentage of nurses regarding courses attendence}

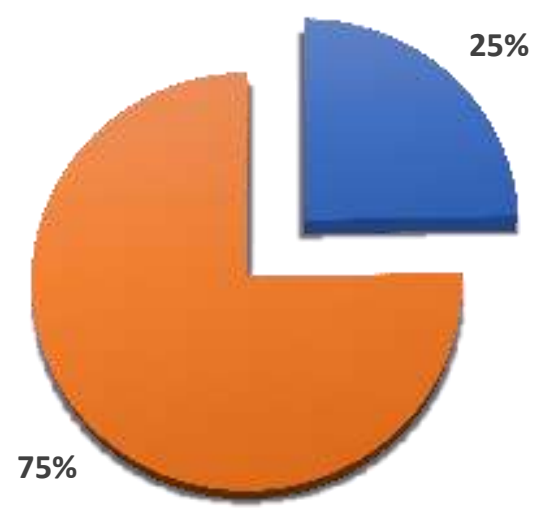

Attended Courses

Did not attend courses

Figure (2): Distribution of nurses according to courses attendance on inotropic drugs $(\mathrm{n}=81)$

\section{Nurses total knowledge scores}

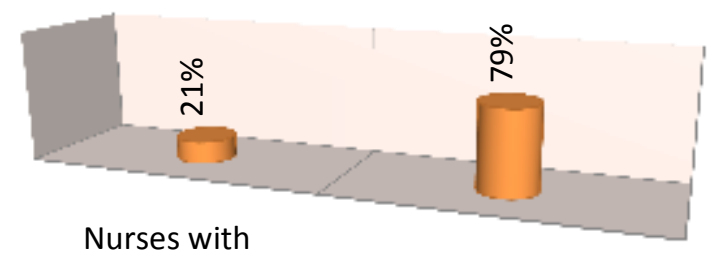

satisfactory total score

Nurses with

unsatisfactory total

score

Figure (3): Distribution of nurses according to total knowledge score $(\mathrm{n}=81)$

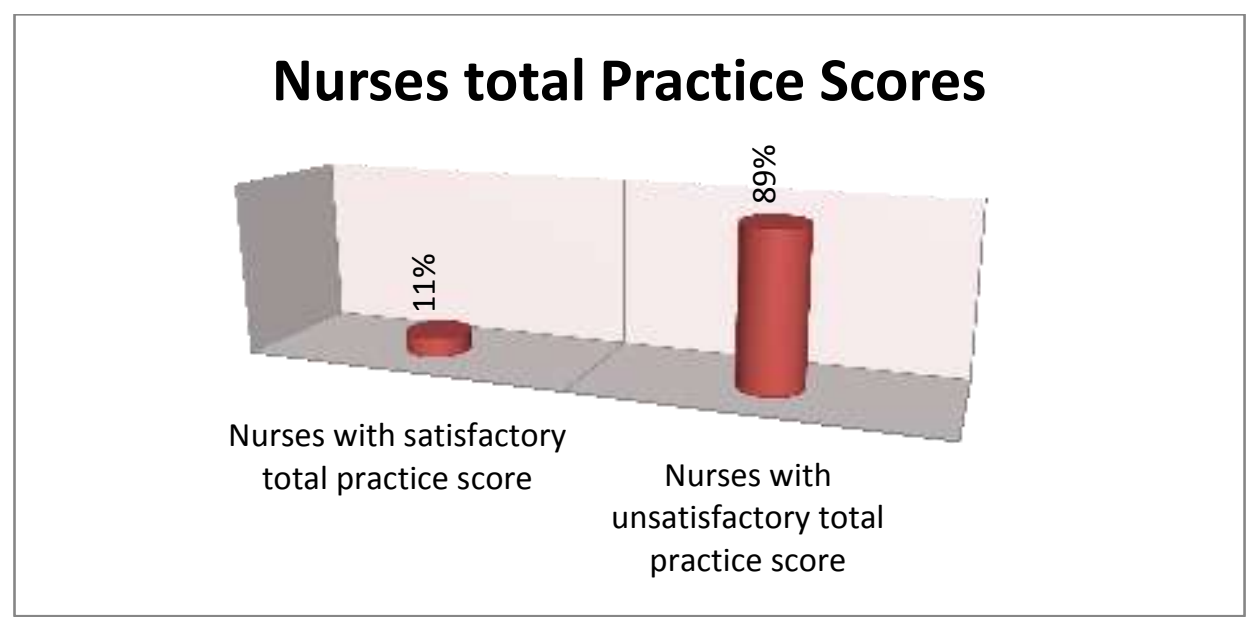

Figure (4): Distribution of the studied nurses according to total practice scores $(\mathrm{n}=81)$ 


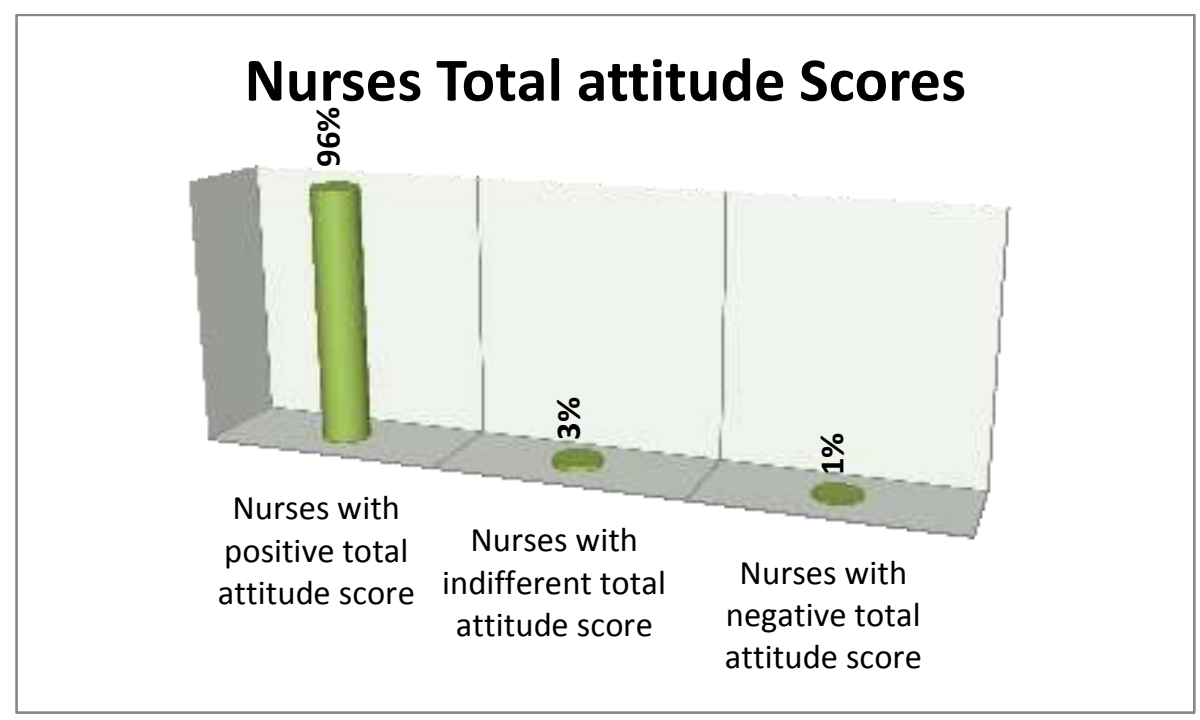

Figure (5): percentage distribution of nurses with positive, indifferent and negative attitude scores $(n=81)$

Table (2): Correlation between total knowledge scores and demographic and work related data

\begin{tabular}{|c|c|c|}
\hline \multirow{2}{*}{ Variables } & \multicolumn{2}{|c|}{ Total Knowledge Scores } \\
\cline { 2 - 3 } & Pearson Correlation & Sig. (2-tailed) \\
\hline \multicolumn{3}{|c|}{ Demographic Data } \\
\hline Age & -0.1 & 0.29 \\
\hline Education & 0.27 & $0.012^{*}$ \\
\hline \multicolumn{2}{|c|}{ Work Related Data } \\
\hline Department & 0.1 & 0.35 \\
\hline Experience & 0.01 & 0.90 \\
\hline Courses & 0.23 & $0.03 *$ \\
\hline
\end{tabular}

\section{* Significant at $\mathbf{p}<0.05$}

Table (3): Correlation between total practice scores and demographic data and work related data

\begin{tabular}{|c|c|c|}
\hline \multirow{2}{*}{ Variables } & \multicolumn{2}{|c|}{ Total Practice Scores } \\
\cline { 2 - 3 } & Pearson Correlation & Sig. (2-tailed) \\
\hline \multicolumn{3}{|c|}{ Demographic Data } \\
\hline Age & 0.043 & 0.705 \\
\hline Education & $0.28^{*}$ & $0.01^{*}$ \\
\hline \multicolumn{3}{|c|}{ Work Related Data } \\
\hline Department & 0.029 & 0.79 \\
\hline
\end{tabular}




\begin{tabular}{|c|c|c|}
\hline Experience & 0.057 & 0.61 \\
\hline Courses & 0.04 & 0.69 \\
\hline
\end{tabular}

* Significant at $\mathrm{p}<0.05$

Table (4): Comparison between total knowledge and total practice

\begin{tabular}{|l|c|c|c|c|c|c|}
\hline \multirow{2}{*}{ Variables } & \multicolumn{2}{|c|}{$\begin{array}{c}\text { Satisfactory } \\
\text { Knowledge score } \\
(\mathbf{n = 1 7 )}\end{array}$} & $\begin{array}{c}\text { Unsatisfactory } \\
\text { Knowledge score } \\
(\mathbf{n = 6 4 )}\end{array}$ & $\mathbf{X}^{\mathbf{2}}$ & p-value \\
\cline { 2 - 5 } & No & $\%$ & No & $\%$ & & \\
\hline Satisfactory & 6 & 35.3 & 3 & 4.7 & & $0.002 * *$ \\
\hline $\begin{array}{l}\text { Unsatisfactor } \\
\text { y }\end{array}$ & 11 & 64.7 & 61 & 95.3 & 12.74 & \\
\hline
\end{tabular}

Table (5): correlation between total attitude scores, total practice and total knowledge scores

\begin{tabular}{|c|c|c|}
\hline \multirow{2}{*}{} & \multicolumn{2}{|c|}{ Total Attitude Score } \\
\cline { 2 - 3 } & Pearson Correlation & Sig. (2-tailed) \\
\hline Total Knowledge Score & $0.25^{*}$ & $0.03 *$ \\
\hline Total Practice Score & $0.26^{*}$ & $0.02 *$ \\
\hline
\end{tabular}

* Significant at $\mathrm{p}<0.05$ 


\section{DISCUSSION:}

Nurses are the last person in the administration process of medication to resolve and prevent the medication administration errors; so, they must be knowledgeable about the effect, rationale and compatibilities of the drug, and calculation of the right dose for patients along with having a work environment that supports this process. Nurses can administer up to 50 medications per shift (Ofosu and Jarrett, 2015 and Grigg et al., 2011). Moreover, examples of frequently used inotropic drugs in the intensive care unit include adrenaline, noradrenaline, dopamine, dobutamine and digoxin. These drugs are very potent, and the results of incorrect administration or excessive doses can be harmful for patients (Hollenberg, 2011).

The current study had answered the research question, entitled" What the level of nurses 'knowledge regarding to administration of inotropic medications for critically ill patients is" and revealed that most of nurses had an unsatisfactory level of knowledge. A possible interpretation of the results may be due to that nursing implications and role about pharmacology were not explained clearly in the curriculum. Also, lack of verification process in nursing pharmacology and dependence of nurses on physicians in drug administration process. Furthermore, this point of view was supported by (AIShara, 2011) who demonstrated lack of nurses' medication competency and unfamiliarity of medication.

In relation to the items of knowledge regarding administering inotropic medication (knowledge related- to inotropic concepts, adrenaline, noradrenaline, dopamine and dobutamine), the results of this study depicted that, most of the nurses had incorrect answer regarding previously mentioned items of inotropic medications. Also, these results resonated well with (Samy, 2014) a study entitled "High Alert Medications among Critically Ill Patients: Assessment of nurses' Knowledge and Practice which revealed that, the majority of nurses had incorrect answers regarding inotropic medications.

Moreover, these results were in agreement with the study done by (Ndosi and Newell, 2009) which showed that the nurses have insufficient knowledge regarding the medications they commonly administer. Furthermore, these results were in correspondence with (Keers et al., 2013) entitled "Causes of medication 
administration errors in hospitals: a systematic review of quantitative and qualitative evidence" which revealed that nurses lack theoretical knowledge.

In the same vein, these results were supported by study done by (Lu et al., 2013) illuminated that the nurses have insufficient knowledge regarding pharmacology. In addition, these results were in accordance with the study done by (Samy, 2014) to assess nurses' knowledge and practices regarding administration of high alert medications which showed that $87.1 \%$ of the studied nurses had unsatisfactory total knowledge emphasized by (Simonsen, 2014) who revealed that, nurses experience insufficient medication knowledge

Moreover, these results concur with (Sallam, 2016) a study entitled" nurses' performance regarding administration of high alert medication" which showed that $62.5 \%$ of nurses had an unsatisfactory level of knowledge. Furthermore, this finding was in the same line with (LU et al., 2013); a study performed to assess nurses' knowledge of high-alert medications which revealed that nurses' knowledge of drug administration errors was insufficient.

Additionally, this study showed that nurses' knowledge of digoxin was unsatisfactory and these results were agreed by (Lan et al., 2014) a study entitled" Medication errors in pediatric nursing: Assessment of nurses' knowledge and analysis of the consequences of errors" which illuminated that, nurses' knowledge regarding digoxin dosages and actions was insufficient.

On the other hand, this study was contradicted with (Nair, 2011) a study done to assess the knowledge of cardiac nurses about commonly administered drugs in cardiac surgical ICU which revealed that, nurses had above average level of knowledge about cardiac drugs they commonly administered.

This study had answered the research question, entitled "What the nurses 'practice regarding to administration of inotropic medications for critically ill patients is and revealed that most of nurses have unsatisfactory level of practice preadministration, during administration and post-administration.

These results could be due to lack of medication knowledge base of nurses. Also, the gap between nurses' knowledge and practice due to lack of translation of knowledge into practice, this point of view is generally supported by (Risjord, 2010) and limitation of medication administration on preparing and giving to the patients. Furthermore, lack of policies and rules that controlling the medication administration process. 
The current study results revealed that there were many unsatisfactory practices related to administration of inotropic medications as more than half of the studied nurses didn't prepare equipment, didn't check prescribed medications, didn't monitor the infusion by checking the volume of fluid infused at least every hour, didn't monitor patients' vital signs during administration of selected inotropic medication in addition to monitoring for extravasation and observing any drug reaction, and this results were in the same line with (Fathi, 2014) that revealed lack of nurses monitoring to infusion and medications.

These results were in the same line with (Westbrook et al., 2011) a study conducted to evaluate intravenous medications administration errors in hospital and the correct procedures role which showed a significant proportion of IV administration errors reflect knowledge and skill deficiencies.

In the same vein, these results were in agreement with (Kumar et al., 2011), a study performed to evaluate errors in medication administration in a tertiary care hospital and depicted that the main human factor responsible for errors in medication administration were clarified as practical deficit supported by (Al-Youssif and Mohamed, 2013), a study that showed related causes for unsatisfactory practice regarding high alert medications to poor communication between nurses and physicians, physicians medication orders were illegible and added that many medications names were similar; different medications look alike, and unavailability of pharmacists 24 hours a day.

The current study results were in identical line with (Westbrook et al., 2011), a study conducted to evaluate intravenous medication administration errors in hospital and the correct procedures role and it showed that there were numerous procedural failures as failure to check patient identification, failure to check pulse/blood pressure before administration, and failure to record medication administration on medication chart.

Moreover , the current results were consistent with (Ghenadenik et al., 2012), a study conducted to evaluate possible risks associated with medication administration and illustrated that incorrect practices related accuracy checking and completing documentation in the medication administration as regard to the prescription, drug dosage and the administration route, medication preparation and labeling it with the appropriate patient identifiers (e.g., name, room number, and patient's file number), 
hand washing before and after medication administration and patient's presence verification and availability to administer the medication.

Furthermore, these results were consistent with ( Sneck et al., 2015) who demonstrated lack of nurses' medication practical skills emphasized by a study done by (Hanafi, 2012), entitled" Knowledge, attitudes and practice of nurse regarding adverse drug reaction reporting which showed that, practice of nurses aren't satisfying.

The current study has answered the research question entitled" What the nurses' attitude regarding to administration of inotropic medications for critically ill patients is and illuminated that, the majority of studied nurses had a positive attitude toward administering inotropic medications.

These results could be due to great enthusiasm that nurses having toward updating their knowledge and reporting medication errors, preventing errors and apply principles of medication safety. Also, these results were in correspondence with (Hanafi et al., 2014) who revealed that high level of nurses' positive attitude toward medication administration.

Moreover, these results were in agreement with (Thomas and Johnson, 2013) a study entitled" Medication Errors: Knowledge and Attitude of nurses which showed a positive attitude toward medication administration. Furthermore, these results are agreed by (Sallam, 2016) a study entitled" nurses' performance regarding administration of high alert medication" which showed that more than half of studied nurses have a positive attitude toward administered inotropic medications.

Additionally, these results were in accordance with (Tangiisuran et al., 2017) a study entitled" Comparison of nurses and general caregivers' knowledge, attitude, and practice on medication administration process and their distress level in long-term care facilities" which showed that, nurses had a positive attitude toward medication administration and reporting errors.

As regards the correlation between total knowledge scores and personal characteristics, the current study revealed that, there was a positive significant correlation between total knowledge scores, education and received courses regarding inotropic medication. Also, these results were in accordance with (Simonsen et al., 2014) a study entitled" Differences in medication knowledge and risk of errors between graduating nursing students and working registered nurses: 
Comparative study" which showed that higher education is correlated with safe drug dose calculations.

Moreover, this finding was in the same line with (Institute for Safe Medication Practices, 2011) that illuminated education as one of the main elements that have the greatest effect on nurses' medication knowledge. Additionally, these results were in the same vein with (Ndosi \& Newell, 2009), which revealed that senior nurses had a significantly higher mean score than the junior nurses and nurses with undergraduate qualifications scored significantly lower scores than those with postgraduate qualifications.

On the same line these results were in the same line with (Qalawa, 2009), who pointed that nurses' knowledge was positively related to level of education. Furthermore, this finding was in contrast with (Shamsuddin and Shafie, 2012) a study entitled" Knowledge of nurses in the preparation and administration of intravenous medications which showed that the knowledge levels of nurses were not affected by level of nursing education.

Concerning the correlation between the nurses' knowledge and courses, the current study illuminated that there was a positive correlation between nurses' knowledge and courses and this study was in line with (Sneck et al., 2015) who demonstrated that there was a positive relationship between in service training and nurses' knowledge.

In relation to the correlation between the nurses' practice and personal data, the current study revealed that, there was a positive correlation between nurses' practice and education and this study was in accordance with (John et al., 2012), a study that showed that, the nurses with baccalaureate degree had slightly higher median practice score than the diploma holders. Moreover, these results were corroborated with (Qalawa, 2009), who pointed that nurses' practice was positively related to level of education. Furthermore, these results were in contrast with (Dilles et al., 2011) that revealed no correlation between school education and nurses' practice in pharmacology.

Concerning the relationship between nurses' practice and nurses' knowledge, the current study illuminated that there was a highly positive correlation between nurses' practice and nurses' knowledge. Also, this result was in some degree of agreement with (Hassan \& Ahmed, 2012), a study entitled "Patient Safety: Assessing Nurses' Compliance" showed that, there were statistical significant correlation between level 
of education and total scores of nurses' safety practices regarding the administration of high alert medications. On the same line, (Shahin et al., 2012), who revealed that, there was a highly statistically significant difference between nurses' practices and their knowledge.

In the same context, the current study revealed that there was a positive correlation between the nurses' attitude and their knowledge and practice. In addition, this result was in harmony with (Sallam, 2016) who reported that, there was a positive relation between nurses' knowledge, practice and attitude. Also, this result was in accordance with (Attia, 2012) who showed positive correlation between nurses' knowledge and attitude.

Dissimilarly, this result was contradicted with (Muzio, 2016) who reported that, adequate medication knowledge and practice is not related to positive attitudes for management of intravenous medications and (Attia, 2012) who showed no correlation between nurses' practice and attitude.

Finally, these results of this study can be interpreted in the light of the fact that medication knowledge and practice and attitude didn't increase linearly, but included more complex and sophisticated process and nurses' performance regarding pharmacology is mostly acquired during their work rather than during formal, infaculty education. Moreover, nurses' medication knowledge and practice vary depending on how often they administer medication in their daily work. Consequently, nurses need to inject the evidence into practice.

\section{CONCLUSION \& RECOMMENDATIONS:}

In the light of the current study, we could conclude that, most of nurses had an unsatisfactory knowledge and practice regarding inotropic medications with the great majority of studied nurses had a positive attitude toward administering inotropic medications.

In the light of these findings, the following recommendations are suggested.

- Provide educational and training programs and upgrading courses supported with evidence based practices and guidelines for administration of inotropic medications.

- Monitor nurses' performance in relation to administration of inotropic medications. 


\section{REFERENCES:}

Allen, J. (2014): Understanding Vasoactive Medications, Journal of Infusion Nursing 37 (2): $82-86$

Al-Shara, M. (2011): Factors contributing to medication errors in Jordan: a nursing perspective. Iranian Journal of Nursing, Midwifery Research, 16 (2): 158-161.

Al-Youssif, A. S., Mohamed, K. L. \& Mohamed, S. N., (2013): Nurses' Experiences toward Perception of Medication Administration Errors Reporting. Journal of Nursing and Health Science, 4 (1): 56-70

Attia, S. (2012): Nurses' performance regarding intravenous infusion of high alert medications. Available at: Depository. asu.edu.eg/xmlilhondle/123456789/307

Dilles, T., Vander Stichele, R.R., Van Bortel, L., and Elseviers, M.M. (2011): Nursing students' pharmacological knowledge and calculation skills: Ready for practice? Nurse Education Today, 31:499-505.

Grigg, S. J., Garrett, S. K., and Craig, J. B. (2011): A process centered analysis of medication administration: Identifying current methods and potential for improvement. International Journal of Industrial Ergonomics, 41: 380-388.

Hanafie, S., Torkamandi, H., Hayatshahi, A., Gholami, K., Javadi, M. (2012): Knowledge, attitudes and practice of nurse regarding adverse drug reaction reporting. Iranian Journal of Nursing and Midwifery Research. 17(1):21-25

Hollenberg, S.M. (2011): Vasoactive drugs in circulatory shock. Am J Respir Crit Care Med., 183 (7): 847-855.

Hassan, M.R. \& Ahmed, .S. (2012): Patient Safety: Assessing Nurses' Compliance. Journal of American Science. 8(1):748- 755

Institute for safe medication practices, (2011):

John, L. J., Arifulla, M., Cheriathu, J. J., and Sreedharan, J. (2012): Reporting of adverse drug reactions: an exploratory study among nurses in a teaching hospital, Ajman, United Arab Emirates. DARU J Pharm Sci, 20:1-6

Keers, R.N., Williams, S.D., Cooke, J. and Ashcroft, D.M. (2013): Causes of medication administration errors in hospitals: a systematic review of quantitative and qualitative evidence. Drug Safety., 36 (11): 1045-1067

Kizior, R. and Hodgson, B. (2016): Nursing Drug Handbook, 21th ed., St. Louis, Elsevier: Pp.883

Lan, H., Wang, K.K., Yu, S., Chen, I.,Wu, H., Tang, F.(2014): Medication errors in pediatric nursing: Assessment of nurses' knowledge and analysis of the consequences of errors. Nurse Education Today, 34 (2014): 821-828 
Lu, M. C., Yu, S., Chen, I., Wang, K. W. K., Wu, H. F., and Tang, F. I. (2013): Nurses' knowledge of high-alert medications: A randomized controlled trial. Nurse education today, 33(1): 24-30.

Muzio, M., Marzuillo, C. Vito C., Torre G. and Tartaglini, D. (2016): Knowledge, attitudes, behavior and training needs of ICU nurses on medication errors in the use of IV drugs, available at http://www.signavitae.com.

Nair, G.S. (2011): A Study To Assess The Knowledge of Cardiac Nurses About Commonly Administered Drugs In Cardiac Surgical Intensive Care Unit. Published master thesis, Sree Chitra Tirunal Institute for Medical Sciences and Technology, Thiruvananthapuram: Pp.39

Ndosi, M. E., and Newell, R. (2009): Nurses' knowledge of pharmacology behind drugs they commonly administer. Journal of clinical nursing, 18 (4):570-580.

Ofosu, R., and Jarrett, P. (2015): Reducing nurse medication administration errors. Nursing Times, 111: 12-14.

Palmer, K. and Trinh, J. (2012): Inotropes. Anesthesia and Intensive Care Medicine, 13 (10): 492-498.

Parry, A. (2015): How to administer inotropic drugs. Journal of Nursing Standard. 30 (4), $36: 39$

Parry, A. (2012): Inotropic drugs and their uses in critical care. Nursing in critical care, 17(1):19-27

Perry, A.G., Potter, P. and Ostendorf, W. (2014): Clinical nursing skills \&techniques, $10^{\text {th }}$ ed., Elsevier Mosby; St. Louis: Pp.475

Sallam, G.K. (2016): Cardiac Nurses' performance regarding administration of high alert medication in coronary care units, published master thesis, Medical Surgical Nursing, Faculty of Nursing, Ain Shams University: P.p110, 119,125

Samy, R. (2014): Assessment of Nurses' Knowledge and Practice among Critically Ill Patients. Published master thesis, Lambert Academic Publishing: Pp.69-70

Shahin, M., Mohammed, W. and Sayed, M. (2012): Nurses' knowledge and practices regarding Enteral Nutrition at the critical care Department of Al-Manial University Hospital in Egypt: Impact of a Deigned instructional Program. Journal of American Science 8(11):402-403 
Sneck, S., Isola, A., Saarnio, R. and Boigu, R. (2015): Medication competency of nurses, according to theoretical and drug calculation online exams: A descriptive correlational study. Nurse Education Today, 36 (2016): 195-201

Simonsen, B. O., Daehlin, G. K., Johansson, I. and Farup, P. G. (2014): Differences in medication knowledge and risk of errors between graduating nursing students and working registered nurses: Comparative study. BMC Health Services Research, 14: 1-11

Sonawane, P., Jagtap, B. and Chaudhury, S. (2016): Inotrope use in critically ill patients: Prevalence and effects on mortality. Pravara Medical Review, 8(4): 4-11

Thomas, M. and Johnson, J. (2013): Medication errors: knowledge and attitude of nurses in AJMAN, UAE, Reviews of Progress, 1(4): 1-6

Westbrook, J., Woods, A. , Rob, M. , Dunsmuir, W. and Day, R. (2011): Association of interruptions with an increased risk of severity of medication administration errors. Archives of Internal Medicine, 170 (8): 683 - 690. 


\section{الخلاصة}

الخلفيه العلميه: ان الاعطاء الغير مناسب لادويه محفز ات القلب قد يؤدى الى اثار ضاره ووخيمه للمرضى ذوى

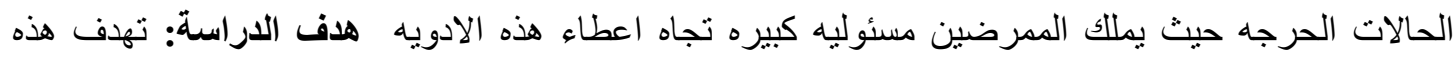

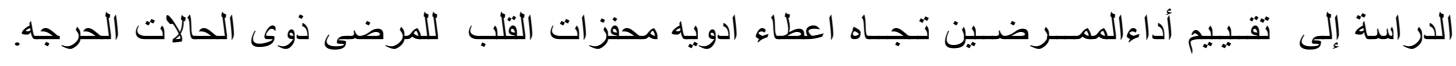

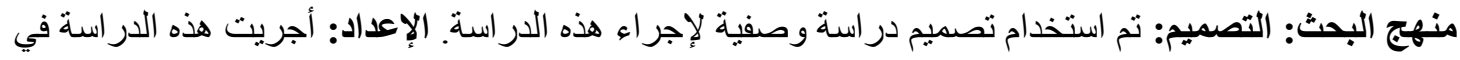
اقسام الرعايه الحرجه في مستشفى قناة السويس الجامعي والمستشفى العام بمدينة الإسماعيلية. الموضوع: عينة من 90 ممرض وممرضه. الأدوات: شملت استبانه البيانات الديموغر افيه واستبيان تقييم المعلومات و استبانه ملاحظه الاداء ومقياس ليكرت .النتائج: معظم الممرضين كان لديهم مستوى غير مرضى بـى بخصوص معلوماتهم(79\%) وممارستهم(89\%) عن ادويه محفزات القلب.معظم الممرضين كان لديهم اتجاهات ايجابيه

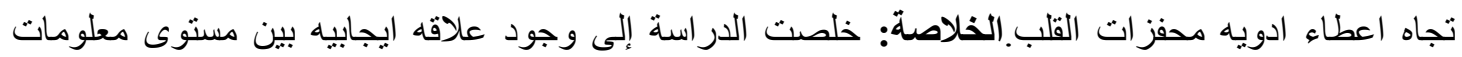
الممرضيين وممارستهمز بالاضافه ايضا وجود علاقه ايجابيه بين مستوى معلوماتهم وممارستهم و اتجاهاتهر. 